\title{
Aligned and Staggered Layouts: What is the Impact on Wind Farms Land-Use?
}

\author{
Rafael Valotta Rodrigues ${ }^{1 *}$, Corinne Lengsfeld ${ }^{2}$
}

\author{
${ }^{1}$ Syracuse University, Mechanical and Aerospace Engineering Department, 123 Link Hall, Syracuse, NY 13244, \\ United States, rvrodrig@syr.edu \\ ${ }^{2}$ University of Denver, Mechanical and Materials Engineering Department, 2155 E Wesley Ave, Denver, CO 80208, \\ United States, Corinne.lengsfeld@du.edu \\ *Correspondence to rvrodrig@syr.edu
}

\begin{abstract}
The use of wind energy has been developing fast over the last years. The global cumulative wind power capacity increased by $10.5 \%$ in 2019 , most of which comes from onshore wind farms. One of the consequences of this continuous increase is the use of land for onshore wind farms. There are already cases worldwide where lack of well-established plans and strategies have caused delays in projects. The need for efficiently using land for wind farms will be mandatory in the short term. In this work, we present a numerical analysis to evaluate wind farm land-use. By defining the ratio between mechanical output power over an area as a parameter called landuse ratio, this work focused on comparing several cases of aligned and staggered layouts. Mechanical output power was estimated using a validated code based on Blade Element Momentum code, and the wake velocities and wake interaction effects were estimated using a validated wind turbine CFD model. In terms of output power, staggered designs are more efficient than aligned designs. However, the results showed that even though staggered designs produced higher output power, aligned farms with tight lateral spacing could be as efficient as staggered ones in terms of land-use but using fewer turbines. In summary, tightly aligned designs should be a tendency in the future towards efficient use of land in wind farms.
\end{abstract}

Keyword: wind farm layout optimization problem, wind farm land-use, wind turbine wakes, wind turbine aerodynamics, tip speed ratio control.

\section{Introduction}

The use of wind energy has been developing fast over the last years. According to GWEC (2020) [1], the global cumulative wind power capacity has reached $651 \mathrm{GW}$ at the end of 2019, which represents a 10.15\% increase compared with 2018 (591GW). The year of 2019 represented only the second time in history that surpassed the $60 \mathrm{GW}$ milestone of yearly added capacity. The onshore market accounted for $54.2 \mathrm{GW}$ of the $60.4 \mathrm{GW}$ added in 2019 , representing a $17 \%$ increase only for onshore compared with 2018 [2]. The onshore market indeed dominates the wind energy industry with a total of $95.5 \%$ in terms of global cumulative wind power capacity. Given the fast growth of onshore wind farms, the use of land for wind energy has been 
Page 2 of 21 “Aligned and Staggered Layouts: Impact on Wind Farms Land-Use”

tremendously increasing. One of the consequences is that many projects that would increase even more the onshore capacity are experiencing delays due to the lack of development of land use plans. For instance, a plan to add $10 \mathrm{GW}$ of onshore capacity in Germany was unable to be completed due to land-use constraints and barriers in getting permits [1]. Another example is the conflict caused by land-use in Brazil, where wind farms located on dune fields and coastal systems restricted community access to natural resources [3]. Aspects such as competing interest for land-use for other purposes and environmental constraints associated with natural wildlife have urged the wind industry to establish clear strategies for land-use in wind farms. Despite of that, no previous efforts in literature have rigorously investigated how to optimize land-use in wind farms.

When dealing with land-use, many issues may arise. Land-use issues include actual land required per energy output or capacity per unit of land area, the amount of land disturbed by a wind farm, non-exclusive land use and compatibility, rural preservation, access roads, location of electrical lines, government regulations and permitting (zoning, building permits, and approval of aviation authorities), and public acceptance [4]. Furthermore, wind energy systems have been limited to areas with consistent wind resources over a long period. In the USA, the development of wind farms has occurred primarily in open areas or rural fields. These are areas often used for agriculture, recreation, scenic areas, wildlife habitat, and forest management. Wind farm facilities in the USA may occupy only 3-5\% of the total acreage, leaving the remaining available for other uses. European wind farms are more efficient in that regard, usually occupying 1-3\% of the land. In the UK, turbines and access roads typically cover $1 \%$ of the land. Actions for mitigating land use in wind farms include the use of equipment with minimal structural support, electrical lines placed underground, maintenance off-site, consolidating equipment on the turbine tower or foundation pad, use of more efficient or larger turbines, optimize turbine spacing to reduce density, roadless construction, restricting most vehicle travel to existing access roads, limiting the number of new access roads. Permitting agencies usually evaluate the cost associated with a particular strategy, type and level of impact, land use-objectives of the community, the significance of any potential land-use inconsistency or incompatibility, and available alternatives [4]. By reducing the amount of land required for wind farms, while still maintaining similar productivity, some barriers to the implementation of new onshore projects can be overcome. Optimization of wind farm land-use will significantly contribute to the more sustainable development of future wind energy projects.

Most of the wind farm optimization efforts have focused on output power, energy production, and costs. One approach that these studies have used to increase power production is to apply control strategies in each rotor [5-7]. Other studies have manipulated parameters of wind turbines, such as pitch angle [7], operation conditions ([9-12]), rotor diameter ([13], [14]), and yaw misalignment ([15 - 20]). Previous efforts in literature have addressed the 
Page 3 of 21 "Aligned and Staggered Layouts: Impact on Wind Farms Land-Use”

influence of spacing between turbines in a wind farm ([21 - 25]), some of which suggest that the current wind farm layout solutions in literature have characteristics with considerably lower spacing than computationally optimized layout solutions [24]. Additionally, reference [23] found that the distance of 10 or 15 diameters between turbines would minimize the cost per unit of energy production. Using these values would result in significant increase in land use, as the values usually applied in wind farms are between 6-10 turbine diameters. Even though these are significant efforts to optimizing output power, energy, and costs, they did not necessarily consider land-use optimization.

Some of the studies on turbine spacing have focused on aligned versus staggered configurations ([26-34]), and most of them have suggested that staggered configurations yield higher output power. In a wind tunnel experimental study [31], the staggered configuration achieved higher overall power generation potential than the aligned one and allowed better wake recovery. Another wind tunnel experiment [33- 34] found that the output power of a staggered second row of turbines was $90 \%$ of the first-row output power for a given streamwise distance of 12 diameters, providing more advantages than the aligned design. Draper \& Nishino [30] found that, when considering output power, staggered designs are more advantageous than the aligned ones. Chamorro et al. [32] found that a staggered layout produced $10 \%$ more output power than an aligned design. Yang \& Sotiropoulos [26] found that staggered layouts are suitable for locations without a prevailing wind direction, while aligned layouts are suitable for wind sites with fixed prevailing wind direction. Even though staggered versus staggered seems to be a critical factor in layout optimization, the referred studies did not address the influence of staggered/aligned designs on land-use. Although there have been many efforts focused on control strategies to enhance output power, energy production, and costs, there is a lack of studies focusing on the problem of improving wind farm land-use and footprint. Previous efforts focusing on wind farm land-use and footprint optimization included landowner modeling with cost-economic analysis [35] and land footprint analysis considering land-use constraint [36]. By analyzing the literature on wind farm land-use, it is clear that there is a need for more investigation on the role of land-use in wind farms. What seems to be the central aspect is to integrate land-use into the investigation of the influence of staggered versus aligned configurations on wind farms.

All these efforts in the literature described above provided relevant contributions to wind farm optimization and turbine spacing research. However, none of them have focused on how to improve wind farm optimization while also reducing land-use. Thus, no previous work in the literature has rigorously addressed the problem of land-use in wind farms. The easiest option to improve energy production in wind farms would be to place turbines far apart from each other to mitigate wake interaction effects. However, this strategy will not achieve the most efficient use of land. Land use is already a problem in some countries, and for others will become a 
Page 4 of 21 "Aligned and Staggered Layouts: Impact on Wind Farms Land-Use”

problem in the long term for the sustainable development of onshore wind energy. This work uses a novel approach of CFD models to investigates the effect of spacing between turbines, both laterally and streamwise, on wind farm land-use. The work focuses on comparing the effects of staggered and aligned configurations on wind farm land-use by evaluating the land-use ratio. The objective is to evaluate turbine spacing in wind farms such that the most efficient use of land can be achieved in wind farms, while still guaranteeing optimized energy production.

\section{Methods}

Various design configurations were evaluated to assess wind farm land-use. For each respective design configuration, key outputs were defined to evaluate each design: 1) Land-Use: total area occupied by a wind farm; 2) Land-Use ratio: kW produced per total area of a wind farm; 3) Wake velocity deficit for each of the wind turbine rows; 4) Total output power. The simulations were performed adopting the designed conditions for the MEXICO rotor $(\omega=424.5 \mathrm{rpm}, \mathrm{U}=15 \mathrm{~m} / \mathrm{s}$ and $\left.\theta=-2.3^{\circ}\right)$, as defined in the report of the MEXICO experiment [37]. To make sure our trends reflect a broader range of operation besides the ones based on the MEXICO rotor, the sensitivity of the land-use ratio to the Tip Speed Ratio (TSR) and to the rotational speed was also assessed. This evaluation is necessary because wind farms experience instantaneous TSR variations during operation, so it is important to know in which level the findings of this work are sensitive to the operational rotational speed. The following sections go into more details on each of the pieces evaluated in this work.

\subsection{Wind Farm Land-Use Ratio}

The wind farm area is the area occupied by all the rows of turbines, which corresponds to be Lx* Ly * nrows in Figure 1, where nrows is the number of rows, Lx is the streamwise spacing, and Ly is the lateral spacing. For the intent of this work, we adopted nrows=3 because of computational limitations: three rows allowed us to get a nuanced effect of the staggered design, while still requiring manageable computational power. For the staggered design, each row had three turbines (2 plus one in the middle of the cluster between the rows), whereas for the aligned design, each row had two turbines. The wind farm land-use ratio was defined based on the ratio between the output power and the area occupied by all the rows of turbines, according to equation (1). Various types of layouts were designed considering staggered (Figure 1a) or aligned (Figure 1b) configurations, in which the spacing Lx and Ly between the turbines were varied, resulting in an increase or decrease of the land-use area. For the aligned design (Figure 1a) analysis, Ly varied within a range from $2 D$ (rotor diameter) to $5 D$, while $L x$ varied within $5 D$ to 15D. For the staggered design (Figure $1 \mathrm{~b}$ ) analysis, Ly varied within a range within 3D to 5D, and $\mathrm{Lx}$ varied within 5D to 15D. Those distances were adopted because they reflect typical distances 
Page 5 of 21 "Aligned and Staggered Layouts: Impact on Wind Farms Land-Use”

in commercial wind farms. The omission of the case in which $L y=2 D$ for the staggered case is because the turbine in the middle of the cluster could have severe issues with wake interaction effects, experiencing a high turbulent wake field with consequences related to components fatigue lifetime.

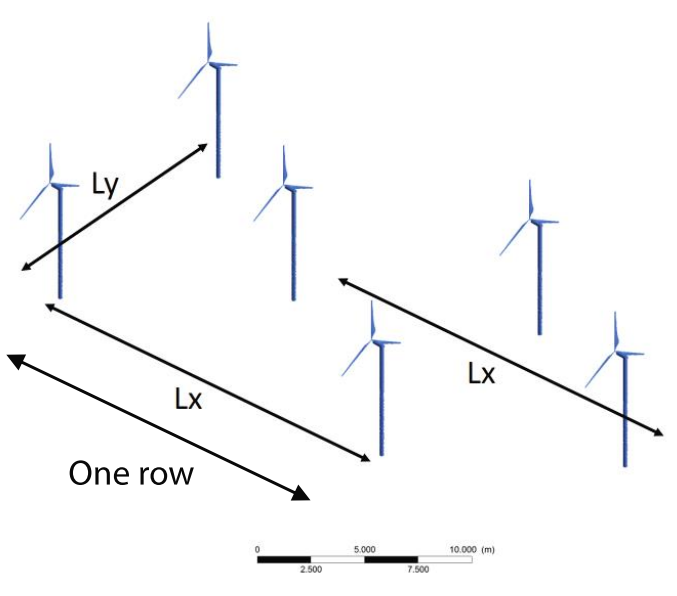

(a)

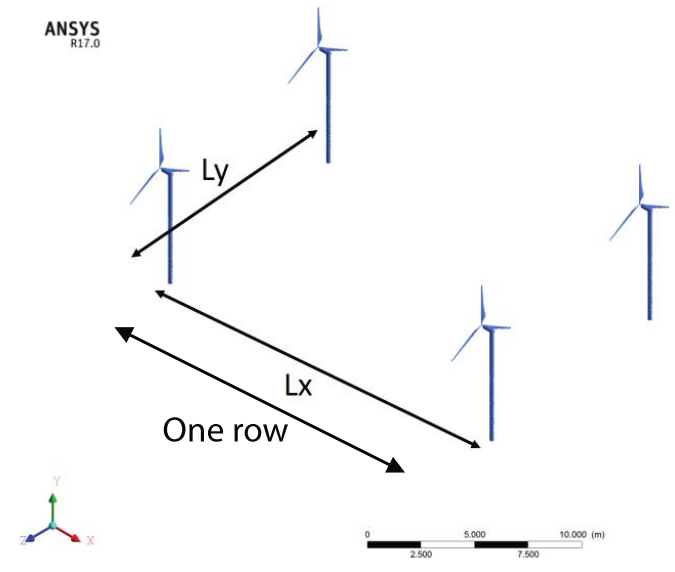

(b)

Figure 1. Wind farm design configurations for a) Staggered design; b) Aligned design. Each row has two and three turbines for the aligned and staggered cases, respectively. The figures show two rows for each design and is omitting the third row used in the analysis.

To calculate the land use ratio, which considers the output power relative to area of land used by all wind turbines combined, we used equation (1):

$$
\text { Land Use Ratio }=\frac{\text { Mechanical Output Power }[\mathrm{kW}]}{\text { Area occupied for all rows of turbines }\left[\mathrm{m}^{2}\right]}
$$

\subsection{Hybrid Approach: CFD and BEM Methods}

In this work, we implemented a hybrid approach to evaluate the wind farm output power: 1) The wake characteristics were evaluated using a CFD model of a wind turbine such that the incident wake velocity could be estimated in a position right in front of each rotor; 2) Taking into consideration the incident velocity in each rotor, the output power was estimated using a computational code based on the Blade Element Momentum (BEM) method. Both codes were validated against experimental data from literature: the CFD model was validated against near wake velocity and rotor thrust data [9], and the BEM code was validated against rotor thrust experimental measurements [37]. The following sections will provide details about each of the methods.

\subsubsection{CFD Model}


Page 6 of 21 "Aligned and Staggered Layouts: Impact on Wind Farms Land-Use”

A wind turbine CFD model of the MEXICO rotor, previously developed and validated against near-wake velocity and rotor thrust data [9], was implemented to estimate wake effects such as wake velocity. After validation, the extended model included the far wake of the wind turbine, and more turbines in the physical domain [10]. Major details of the CFD model implemented (e.g., geometry and mesh sensitivity study) in this work can be found in the literature [9-10]. The blade geometry, including twist angle and variable chord, was modeled using SolidWorks, and then imported to ANSYS Design Modeler to build the other turbine components (tower, hub) and the physical domain. The dimensions $L x$ and Ly dictated the size of the domain for each design. A rectangular block was built and broken into smaller pieces. By defining them as the same part in ANSYS Design Modeler, local meshing for the near and far wake avoids dealing with local mesh gradients at the interfaces on the several rectangles. The mesh was composed of unstructured triangular elements for both the rotor and the near and far wake, using a sphere of influence surrounding each rotor. The mesh sensitivity study is available in literature [9 - 10]. The approach to simulate the rotation of the wind turbine uses a steady-state Moving Reference Frame (MRF) approach. The steady-state MRF approach for the CFD solver allows the user to set up a rotational speed value for the wind turbine to analyze off-design conditions. The wind resource incident on the first row of wind turbines and the rotational speed for all rotors is set in the CFD solver to match the same experimental conditions of the MEXICO rotor $\left(\omega=424.5 \mathrm{rpm}, \mathrm{U}=15 \mathrm{~m} / \mathrm{s}\right.$ and $\left.\theta=-2.3^{\circ}\right)$. The experimental conditions aforementioned corresponds to the designed condition for the MEXICO rotor, which results in the highest aerodynamic performance. There is no velocity gradient in any direction for this simulation. Additionally, we tested the wind farm land-use ratio's sensitivities to the TSR (or rotational speeds) conditions. The turbulence model selected was the k- $\omega$ SST, which is suitable for swirl flow and used in the literature studies as their main turbulence modeling technique. Additional setup included pressure-far-field boundaries for the lateral and superior boundaries (which require the larger exterior rectangle to achieve convergence), pressure-outlet for the exit, and a special type of wall with no shear for the inferior boundary. The flow field solution is determined using the CFD solver ANSYS Fluent17, two computers with 64GB RAM/ 8 processes for each machine with the processor Intel Xeon CPU E5-1620 v2 3.7GHz. The computational time for each simulation was approximately 10 hours. The approach adopted to simulate wake interaction effects between rows was first introduced in reference [10]. Each row is solved separately, taking an output from the outlet of the previous row to use as the inlet of the next row. Essentially, the outlet of the 1st row becomes the inlet of the 2 nd row though the definition of a profile function. The same happens for the 3 rd row, which uses the outlet from the 2 nd-row simulation. A sketch of the blade geometry, physical domain, and computational mesh can be found in references [9] and [10], as well as in the Appendix. 
Page 7 of 21 “Aligned and Staggered Layouts: Impact on Wind Farms Land-Use”

\subsubsection{BEM Model}

The method to estimate output power relied on a model using the Blade Element Momentum (BEM) theory to estimate mechanical output. Figure 2 shows the aerodynamic conventions for the BEM model developed in this work. The implementation of the code includes a set of equations is to estimate the induction factors (Equations 2 to 7), and a 7-steps iterative algorithm [38] (Figure 3). Lift and Drag data were consulted in the literature [39]. Equation 8 represents the mechanical output power production from each segment, and the total mechanical output power is the sum of the contribution of each blade segment multiplied by the rotational speed. The relative velocity in Equations 9, 10, and 11 is a function of the axial (a) and tangential induction factors $\left(a^{\prime}\right)$, dependent on the local velocity in each blade segment. Figure 3 shows a diagram of the algorithm implemented by the code, where $\Delta a=0.005$. The code took around only five iterations to converge, and Figure 4 (in the Results section) shows the validation of the code implemented in this work against experimental rotor thrust data.

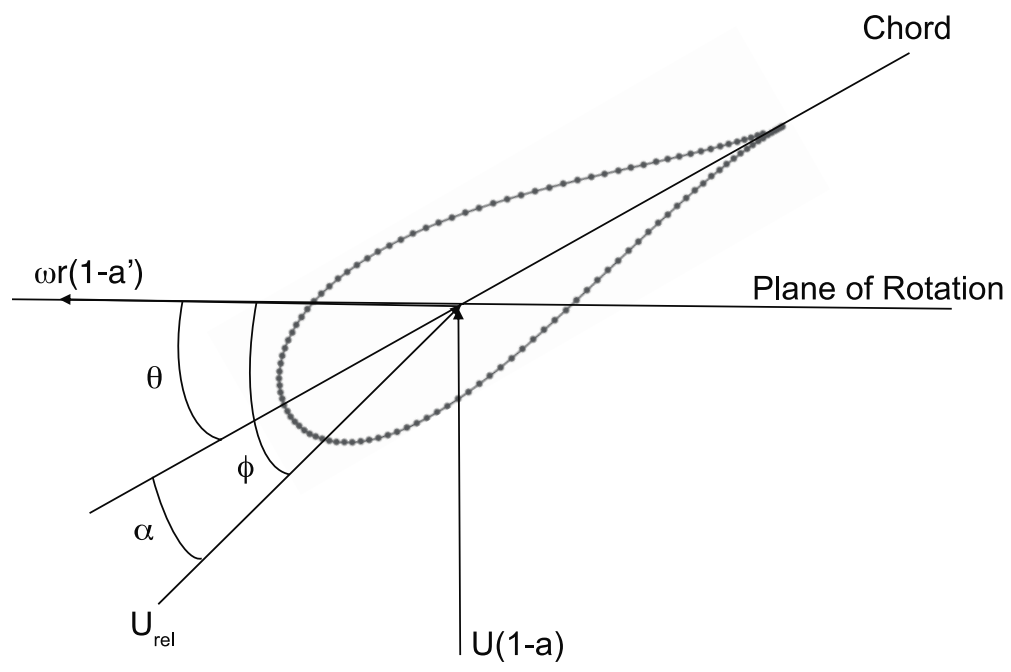

Figure 2. Aerodynamics definitions and signal convention to develop the numerical code based on Blade Element Theory.

$$
\begin{aligned}
& \tan \phi=U(1-a) / \omega r\left(1+a^{\prime}\right) \\
& \alpha=\phi-\theta \\
& C_{n}=C_{l} \cos \phi+C_{d} \sin \phi \\
& C_{t}=C_{l} \sin \phi+C_{d} \sin \phi \\
& a=1 /\left[1+4(\sin \phi)^{2} / \sigma C_{n}\right]
\end{aligned}
$$


Page 8 of 21 "Aligned and Staggered Layouts: Impact on Wind Farms Land-Use”

$$
\begin{aligned}
& a^{\prime}=1 /\left[1+4(\sin \phi \cos \phi) / \sigma C_{t}\right] \\
& d P=0.5 \rho B U_{r e l}^{2} C_{n} c r d r \\
& U_{r e l}=U(1-a) / \sin \phi \\
& U_{r e l}=\omega r\left(1+a^{\prime}\right) / \cos \phi \\
& U_{r e l}=U(1-a) / \omega r\left(1+a^{\prime}\right)
\end{aligned}
$$

Where a: axial induction factor; $a^{\prime}$ : tangential induction factor, $\phi$ : flow angle; $\omega$ : rotor rotational speed; $r$ : local radius; U: free-stream velocity; $\sigma$ : blade solidity; $B$ : number of blades, $P$ : Mechanical Power.

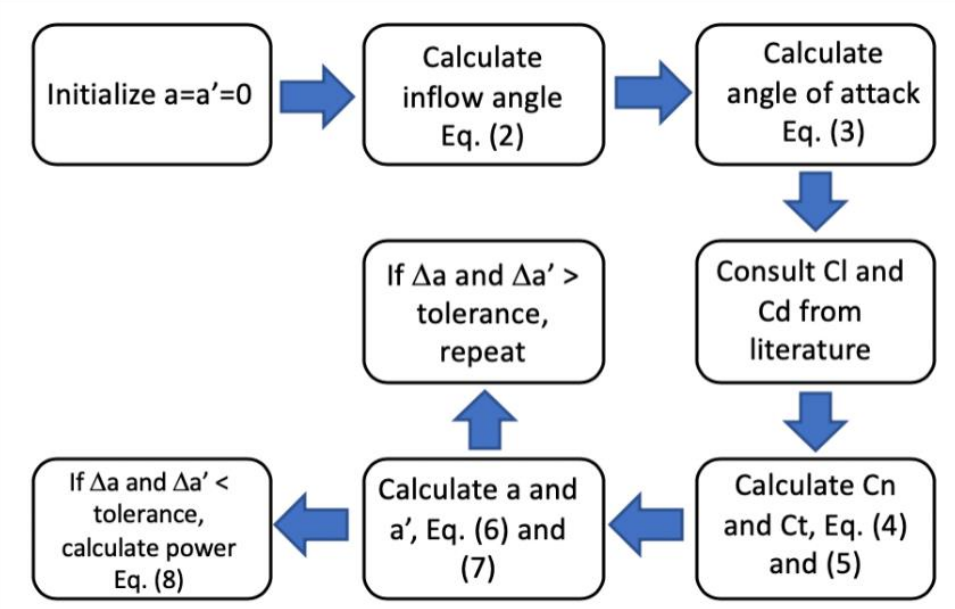

Figure 3. Workflow of the 7 steps iterative process proposed by Hansen ${ }^{113}$.

\section{Results}

\subsection{Validation of the BEM Code}

Figure 4 shows the validation of the code implemented in this work against experimental rotor thrust data. The data from the computational code implemented in this work mostly agrees with the MEXICO rotor experimental data, demonstrating the effectiveness of the tool to estimate mechanical output power. In the region closer to the root of the blade, the data have a better agreement compared to the region closer to the blade tip. The data for the designed condition (Left: $U=15 \mathrm{~m} / \mathrm{s}, \mathrm{TSR}=6.6$ ) have a better agreement than the other condition analyzed (Right: $U=10 \mathrm{~m} / \mathrm{s}, \mathrm{TSR}=10$ ). As there is no availability of experimental data for the mechanical 
Page 9 of 21 "Aligned and Staggered Layouts: Impact on Wind Farms Land-Use”

output power, the only way to validate the BEM code is to perform such a comparison against experimental rotor thrust data.
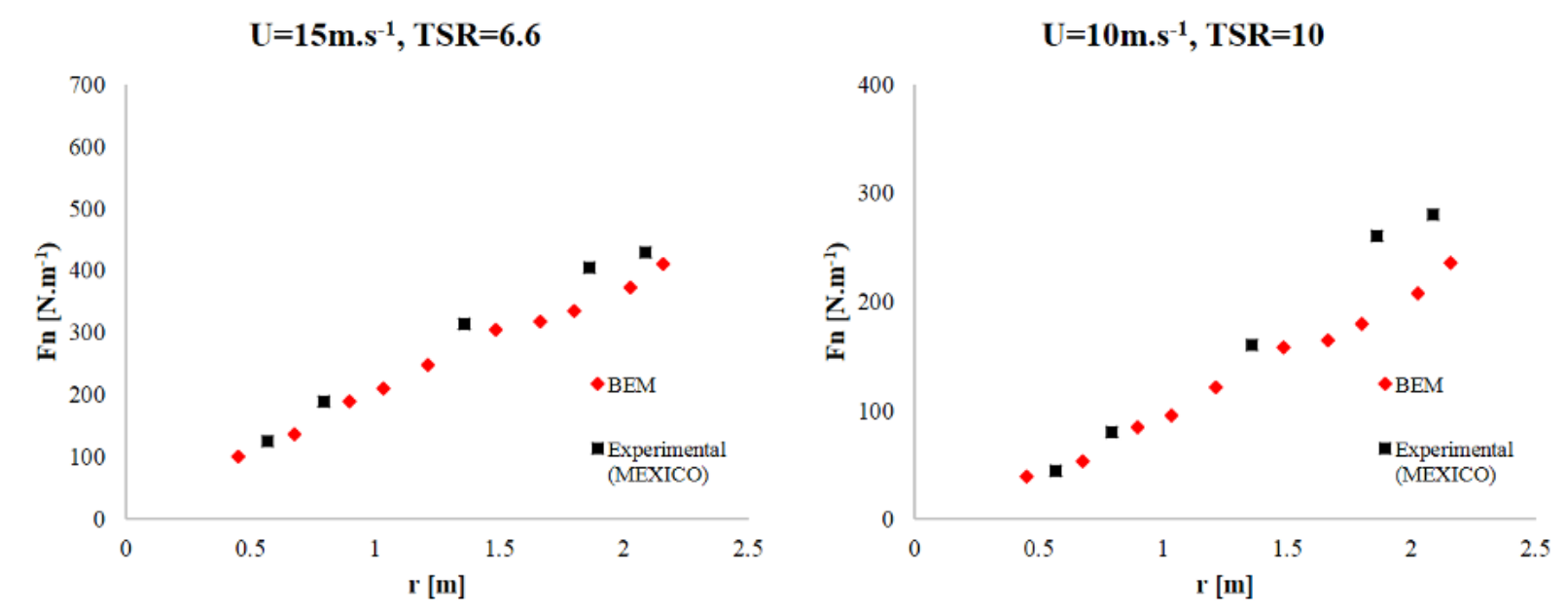

Figure 4. Validation of the BEM code for the MEXICO rotor considering rotor thrust measurements. Experimental data were consulted om reference [30].

\subsection{Land-Use: Staggered vs Aligned}

Figure 5 presents the land-use ratio for aligned and staggered designs as a function of the streamwise distances between rows. Each of the curves represents a different lateral spacing (Ly) condition. These graphs provided some critical trends to characterize the use of land in wind farms. Decreasing the streamwise spacing ( $L x$ ) between rows can be an alternative to improve the efficiency of land use in wind farms. Even though a tighter streamwise spacing between rows leads to lower incident velocity on further rows due to lower wake velocity, a decrease in the area makes the land-use ratio more efficient. The slope of the curves in Figure 5 shows improvement on the land-use ratio within approximately $7.5 \%$ and $13.5 \%$ per diameter. Decreasing lateral spacing (Ly) between rotors in the same rows plays a critical role in improving wind farm land-use. There is still a portion of wake interaction effects between 2 and 3 diameters of lateral spacing for the aligned design. Beyond 3D, wake effects no longer have significant interaction, and the relationship that represents the percent of improvement in land-use per diameter becomes approximately constant and around 33\% per diameter. Thus, wind farms with tighter lateral spacing (Ly) between rows are much more efficient regarding land-use. 
Page 10 of 21 "Aligned and Staggered Layouts: Impact on Wind Farms Land-Use”

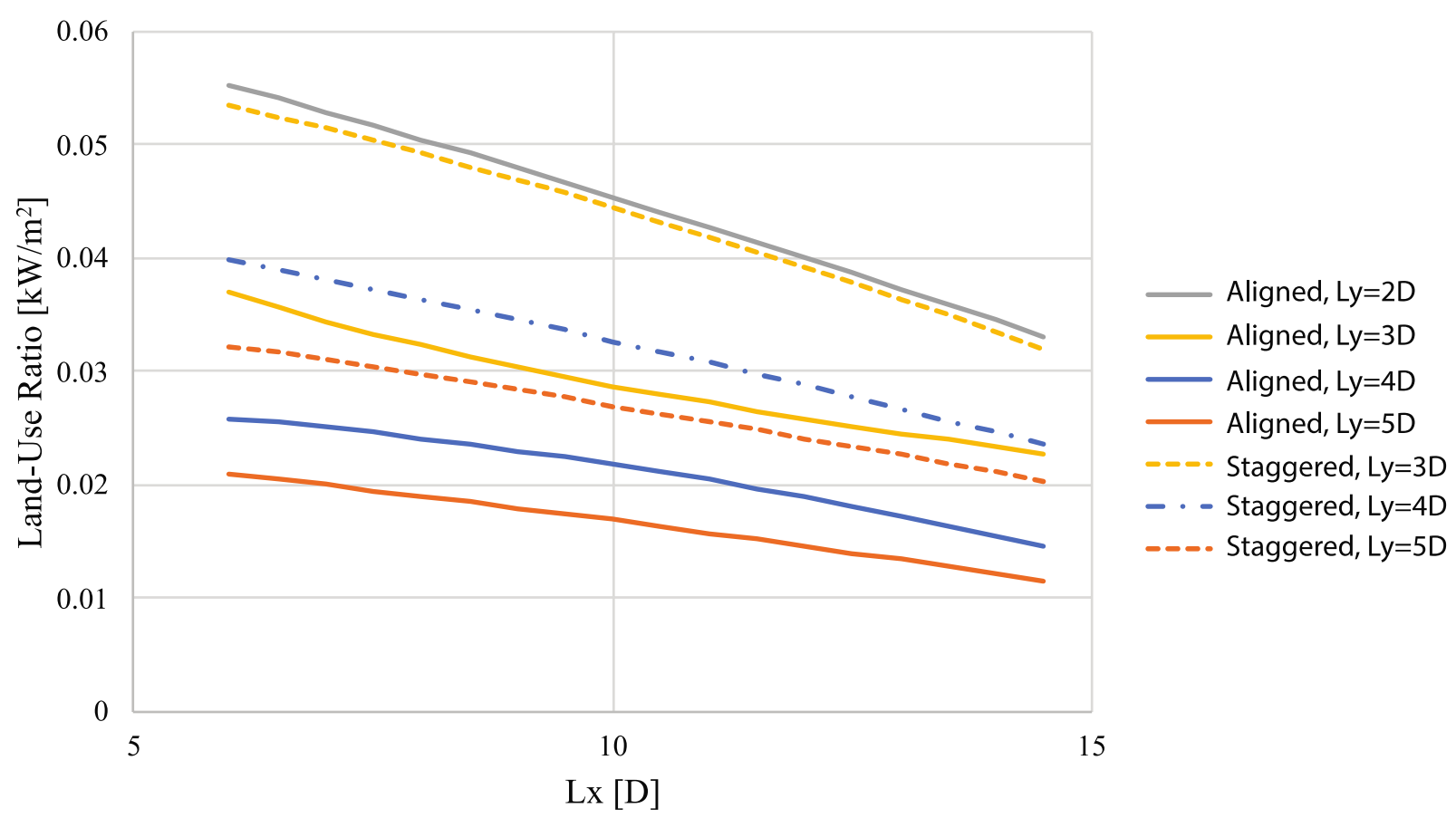

Figure 5. Land-Use of aligned and staggered design configurations, and the spacing Effect under the same TSR and Ufreestream conditions.

The percentage of improvement of the land-use ratio per diameter is more sensitive to Ly than $L x$ because there is no variation of the wake velocity for Ly, meaning that only the area varies and not the output power. On the other hand, Table 1 shows that as Lx increases, the total output power increases (wake velocity increases) while also increasing the land area, resulting in smaller changes in land-use ratio with changes in Lx. Staggered designs with very tightly spaced rotors in the same row (Ly) may have severe issues for turbulence intensity (which will reflect on the fatigue lifetime of the components) as well as decreased output power for the turbine in the middle of the cluster. In comparison, aligned designs do not experience as pronounced issues due to tightly spaced rotors as staggered ones. Because of the staggered design spacing sensitivity, we excluded the option of a 2D laterally spaced staggered turbines in this work. Figure 5 shows a key finding: an aligned design 2D laterally spaced produces a similar land-use ratio compared to staggered designed 3D laterally spaced. As each row in the staggered design has an extra turbine compared with the aligned design, this result means that in the most tightly spaced designs, the aligned design would need fewer turbines to achieve the same levels of land-use ratio as the staggered design. Thus, the aligned design would be the most cost-effective option. 
Page 11 of 21 "Aligned and Staggered Layouts: Impact on Wind Farms Land-Use"

Table 1: Estimated mechanical output power produced by aligned or designed designs, both with $L y=4 \mathrm{D}$.

\begin{tabular}{|c|c|c|c|c|c|}
\hline Cases & $\mathbf{L x}(\mathbf{m})$ & $\mathbf{P}[\mathbf{k W}]_{\text {1st row }}$ & $\mathbf{P}[\mathbf{k W}]_{\mathbf{2 n d} \text { row }}$ & $\mathbf{P}[\mathbf{k W}]$ 3rd row & $\mathbf{P}[\mathbf{k W}]_{\text {total }}$ \\
\hline Aligned & 12 & 29.66 & 16.31 & 11.46 & 57.42 \\
\hline Staggered & 12 & 44.49 & 24.465 & 17.19 & 86.145 \\
\hline Aligned & 9 & 29.66 & 14.12 & 8.13 & 51.92 \\
\hline Staggered & 9 & 44.49 & 21.18 & 12.195 & 77.865 \\
\hline Aligned & 7 & 29.66 & 11.26 & 3.94 & 44.86 \\
\hline Staggered & 7 & 44.49 & 16.89 & 5.91 & 67.29 \\
\hline
\end{tabular}

As commented in the previous paragraph, staggered designs that are too tight laterally (Ly) can have severe issues by inducing a highly turbulent wake field, as well as a more significant wake velocity deficit. Figure 6 shows the velocity and turbulent kinetic energy contours for two staggered cases: $L y=3 D$ and $L y=4 D$. It is easy to see that for the case of $L y=3 D$, the wake interaction effects are more substantial. In the middle of the cluster between the first row and the second row, the wake of the staggered turbine interacts with the wake of the first two previous rotors. The effects felt by the second row are much stronger than the effects experienced by aligned designs. The third-row experiences even more turbulent wake field, and the wake velocity field can be compromised with severe wake velocity decay. The consequences on the output power and turbine components fatigue lifetime can be severe. 
Page 12 of 21 "Aligned and Staggered Layouts: Impact on Wind Farms Land-Use”
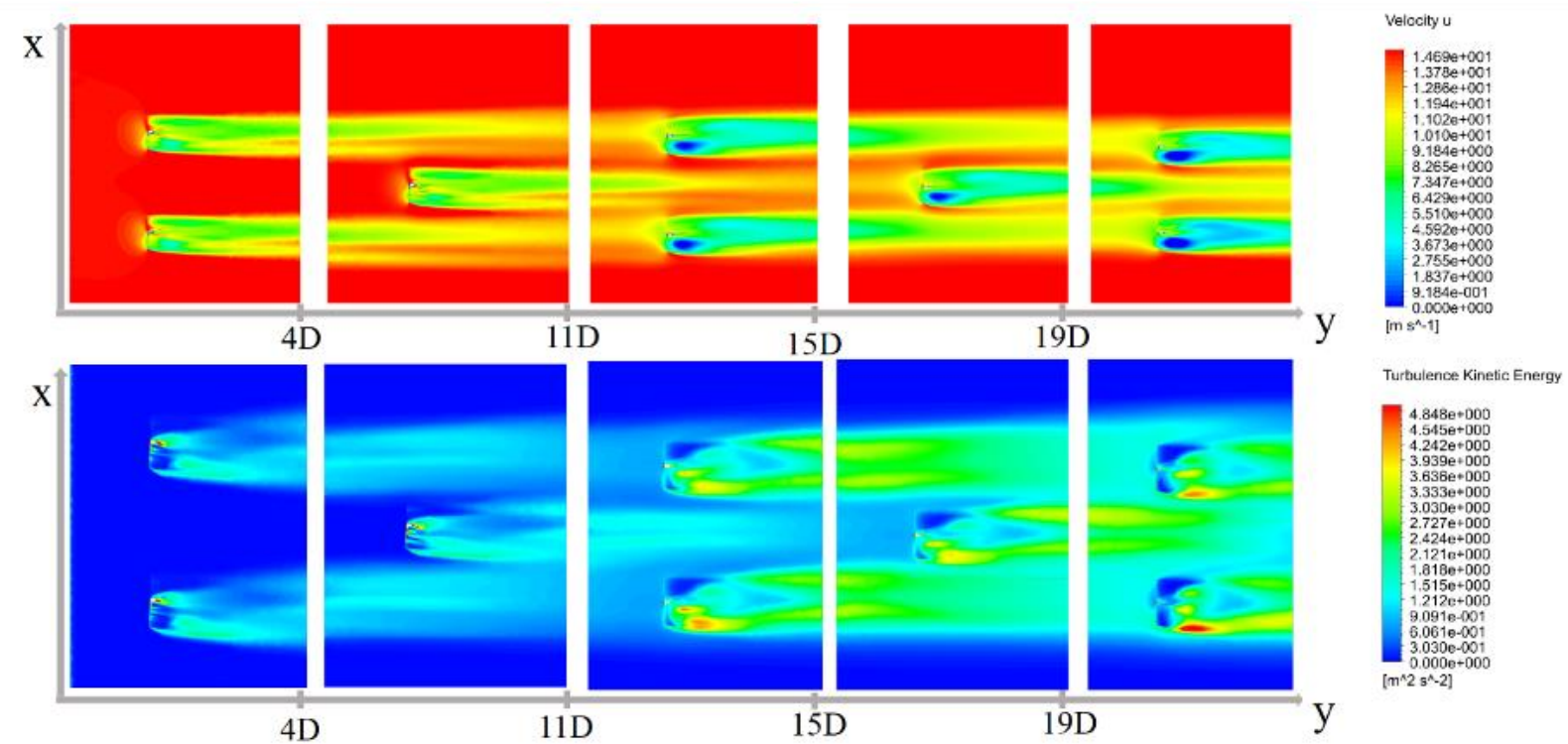

(a)
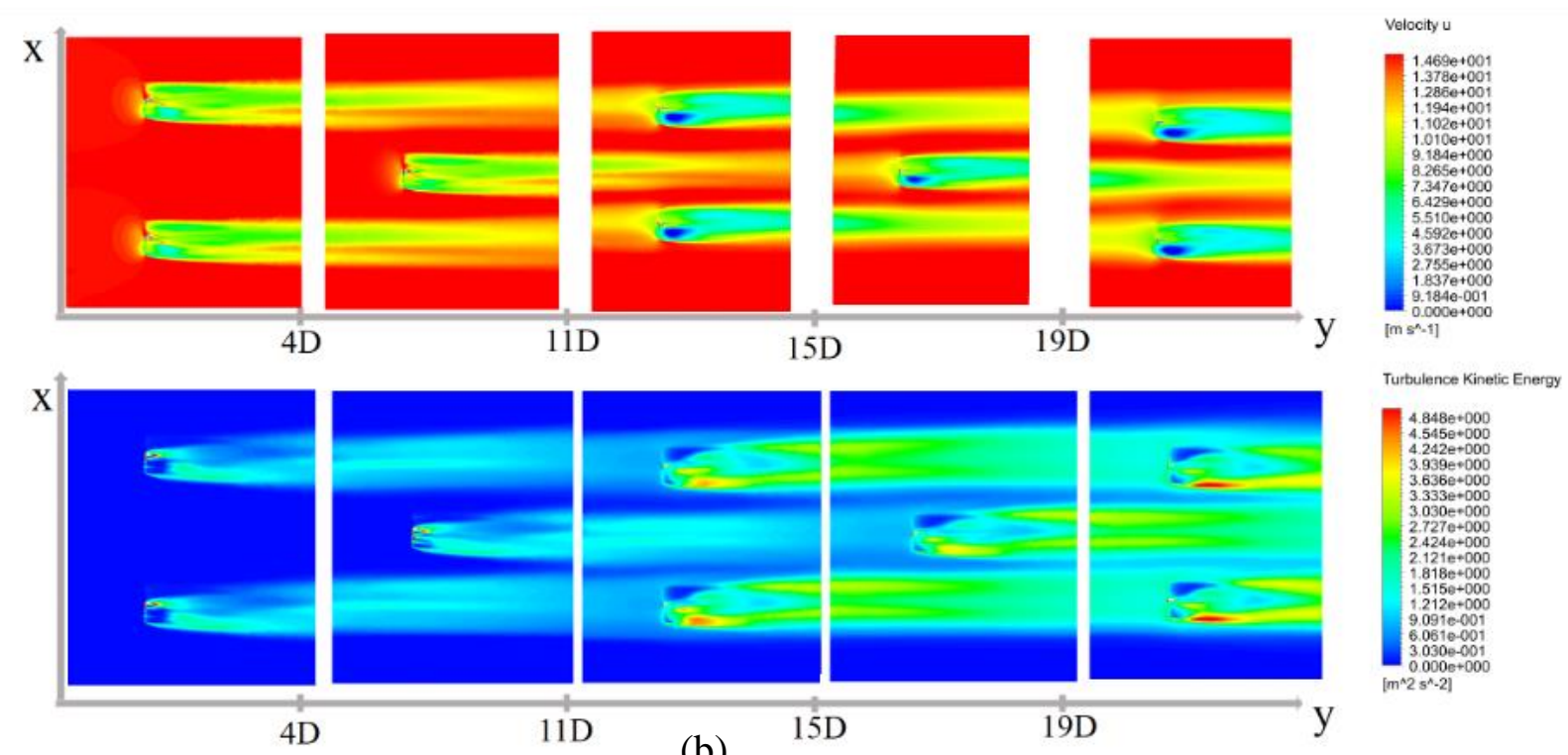

Figure 6. Velocity and Turbulence Intensity Contours for staggered designs with: $a) L y=3 D$; and b) Ly=4D.

\subsection{Sensitivity of Land-Use to TSR Control}

The estimation of the land-use ratio is sensitive to the turbines operating conditions, including TSR and Free-Stream Wind Velocity (Ufree-stream). Here in this section, the goal is to show in which level the ratios estimated in the previous section are sensitive to the TSR of the turbines, and the free-stream velocity $(U)$. Table 2 shows an example of the aligned-design case, considering the same wind condition (Ufree-stream $=15 \mathrm{~m} / \mathrm{s}$ ) and spacing ( $\mathrm{Lx}$ and Ly). In 
Page 13 of 21 "Aligned and Staggered Layouts: Impact on Wind Farms Land-Use”

comparison with the design condition $(15 \mathrm{~m} / \mathrm{s}$ and $\mathrm{TSR}=6.6)$, the land-use ratio $\left(\mathrm{kW} / \mathrm{m}^{2}\right)$ varied $7.6 \%$ for a TSR $=4$, and $16 \%$ for a TSR=5. The variation in the total estimated mechanical power happens because even though the first row of turbines produces less mechanical output power for lower TSR values, the wake velocity is higher. As a consequence, the second and third rows have a higher mechanical output power. Even though we demonstrated that the land-use ratios indicated in the previous section are sensitive to the operating conditions, the trends pointed out in Figures 5 remain valid. The only aspect that would change in Figure 5, for instance, would be a vertical shift in all the curves.

Table 2: Sensitivity of the land-use ratio to the TSR, considering the aligned-turbines design.

\begin{tabular}{|c|c|c|c|c|c|}
\hline $\mathbf{U}_{\text {freestream }}[\mathbf{m} / \mathbf{s}]$ & TSR 1st row & $\mathbf{L y}(\mathbf{m})$ & $\mathbf{L x}(\mathbf{m})$ & Ratio $\mathbf{( k W / \mathbf { m } ^ { 2 } )}$ & $\mathbf{P}[\mathbf{k W}]_{\text {total }}$ \\
\hline 15 & 6.6 & $4 \mathrm{D}$ & 7D & 0.025 & 44.86 \\
\hline 15 & 5 & $4 \mathrm{D}$ & 7D & 0.029 & 47.84 \\
\hline 15 & 4 & $4 \mathrm{D}$ & 7D & 0.0269 & 51.78 \\
\hline 10 & 6.6 & 3D & 9D & 0.009 & 15.34 \\
\hline
\end{tabular}

\section{Discussion}

Even though the output power production increases as we further increase the spacing between rows, the area will increase in this case. Increasing the wind farm area is a problem because wind energy is growing and developing fast, and the offer of the windiest and most profitable sites will be shrinking in the long term. Besides, some of the land-use barriers associated with the development of onshore wind farms also require clear strategies. It will be mandatory to consider using more compact designs to use land most efficiently. There are no well-established universal standards for wind farm spacing. For instance, typical dense arrays in California have up to 6 to 7 hectares (15 to 18 acres) per megawatt of installed capacity, whereas typical European wind farms generally occupy 13 to 20 hectares (30 to 50 acres) per megawatt of installed capacity [3]. A map showing the placement and the location of all wind turbines in the USA can be found in the literature [40], and it is easy to recognize that there is neither standardized spacing distance between the turbines nor consistency in layouts symmetry. Currently, there is a lack of a protocol and long-term plans towards more efficient use of land in onshore wind farms.

This work demonstrated the level of improvement achieved in wind farm land-use when comparing staggered and aligned designs. When designing a wind farm, it is common to assume that a staggered design would be more advantageous because of the higher output power production. However, Figure 5 demonstrated that, depending on the spacing between rows, tightly aligned farms (both laterally and streamwise) could achieve similar land use ratios 
Page 14 of 21 "Aligned and Staggered Layouts: Impact on Wind Farms Land-Use”

$\left(\mathrm{kW} / \mathrm{m}^{2}\right)$ compared to staggered farms, but with the advantage of using fewer turbines. Thus, tightly aligned farms will positively impact project costs since fewer turbines would be required to produce the same wind farm ratio. All in all, more compact aligned farms should be a tendency in the long-term future for onshore wind farms.

Our current study shows new insights on efficiently designing wind farm layouts, taking into consideration land-use aspects. We demonstrated that, depending on the spacing, aligned designs can be as efficient as staggered ones but using fewer turbines, which will have a better cost-benefit. One can point out that we did not consider staggered farms with $L y=2 D$, which would decrease the area and improve the wind farm land-use ratio. We chose not to use this layout based on findings from the literature [29] showing a severe increase in fatigue loads on downstream rows for staggered farms due to wake interaction effects. Figure 6 shows the effects that tightly spaced staggered configurations can produce on the wake, showing that wake interaction effects increase for lower lateral spacing (Ly) values.

The literature shows possibilities of improvements in turbine spacing, but none of these contributions specifically addressed the problem of efficiently using land in wind farms. As a rule, they all focused on output power, energy production, or costs. For instance, Draper \& Nishino [30] found staggered designs to be more advantageous for output power. Similarly, Hamilton et al. [33, 34], Chamorro et al. [32] and Markfot et al. [31] found advantages of staggered configurations for the output power. Importantly, Meyers \& Meneveau [24] and Stevens et al. [23] achieved similar findings that the current wind farms layout solutions in literature have characteristics with considerably lower spacing than computationally optimized layout solutions. Thus, wind farms should use more land area than they currently use to achieve more energy production. The idea in this work of investigating lateral and downstream spacing and its impact on land-use is based on the findings by Stevens et al. [23] and Meyers \& Meneveau [24]. Increasing land use for wind farms is currently non-realistic for many countries that already have restrictions on land use and will probably be a problem for most countries in the future.

Wind farm land-use can be improved not only by designing optimal layouts but also by using Tip Speed Ratio (TSR) control or adjusting operating conditions. Indeed, TSR control can be promising in the future to achieve better land-use efficiency. Table 2 briefly showed that the wind farm land-use ratio could achieve $16 \%$ improvement by implementing TSR control. These results were consistently comparable with data from the literature. Some examples in the literature showed the benefits of reducing output power from upstream turbines to enhance the total farm output power due to increasing the amount of available power for downstream rotors. Pitch Angle and yaw angle control have also been demonstrated effectiveness on output power enhancement. For instance, the optimization of Pitch Angle performed by Lee et al. [15] resulted in $4.5 \%$ improvement, whereas the optimization of both the TSR and Pitch Angle performed by González et al. [6] resulted in 7.55\%. Kazda et al. [16] achieved a 9.7\% increase in the sum of the 
Page 15 of 21 "Aligned and Staggered Layouts: Impact on Wind Farms Land-Use”

upstream and downstream turbines by applying sub-optimal operation for the upstream rotor, operating with a $12.5 \%$ reduction in output power production. Gil et al. [7] achieved up to $6.24 \%$ in energy captured using sub-optimal operating points. Gebraad et al. [20] demonstrated enhancement of $5 \%$ in AEP for a wind farm by combining wake steering control and layout optimization. The findings of all these referred studies are numerically consistent with the findings from Table 2. These examples show that the benefits of controlling wake conditions should be explored in the future, opening new possibilities of control strategies to suggest better solutions for the wind farm optimization problem.

This work approached the novel problem of improving wind farm land-use. Possible limitations of this work arise from the CFD model implemented to evaluate wake characteristics, the number of rows evaluated, and the impact that the turbulence wake field can have on components fatigue lifetime. First, it is essential to have further work using other CFD modeling techniques to estimate the wind farm land-use ratio. In this work, we simplified this task by using a steady-state model previously validated against experimental results. However, there is room for improvement using transient models such as Large-Eddy Simulation (LES) ([26], [41]), but always considering that the more complex the model is, the higher the computational costs. Additionally, considering complex terrain effects (such as the model introduced in [42], and reference [43]) can be a further contribution to evaluate the extent in which the findings pointed out in this work are valid in other circumstances. Moreover, introducing atmospheric boundary layer effects in the model can be an important further improvement. As pointed out by Veers et al. [44], one of the grand challenges in wind energy is to improve the understanding of the atmospheric flow, therefore LES models could give further insights on the role of the atmosphere on wind farm land-use. Second, even though we considered the turbulence wake field in our plot of the wake contours (Figure 6), further investigation is needed in future works to correlate wind farm land-use ratio and components fatigue lifetime. For instance, Tian et al. [29] found that staggered farms considerably increased fatigue loads on downstream rows because of the wake interaction effects. Third, a possible limitation arises from the fact that the model in this work considered three rows of turbines to explore better layout design options. The goal was to reduce the demand for computational resources, while still analyzing such a complex problem of wind farm layout. According to Stevens [24], the optimal spacing depends on wind farm length, which is dependent on the number of rows. Future research could increase the number of rows to get a better sense of the impact of additional rows on the wind farm land-use ratio.

\section{Conclusions}

For the first time in literature, a WFLOP focused on evaluating and improving land-use. This work evaluated wind farm layout design and its implications on wind farm land-use, defined by the ratio between mechanical output power and the area occupied by the wind turbine rows. 
Page 16 of 21 "Aligned and Staggered Layouts: Impact on Wind Farms Land-Use”

A literature review on turbine spacing showed that the options for layout are essentially staggered and aligned configurations. By implementing validated computational codes to estimate mechanical output power according to the incident wake velocity, this work focused on estimating the wind farm land-use as a function of turbine spacing (lateral and streamwise). As a rule, staggered layouts (Figure 1a) produce more output power than aligned farms under the same operating conditions because of the extra turbine in the middle of the cluster (Figure 1). However, staggered layouts should not be as tight as aligned ones in lateral spacing (Ly) because the staggered turbine in the middle of the cluster would experience increased turbulence wake field and reduced mechanical output power. As a consequence, staggered farms may need more area. We found that tightly spaced aligned configurations can produce almost the same values of wind farm land-use ratio compared to staggered ones. A comparison between a tightly spaced $(L y=2 D)$ aligned configuration and a staggered $(L y=3 D)$ one shows similar wind farm land-use ratios, even though the referred aligned case uses fewer turbines than the staggered one. The mechanical output power of the referred aligned case was lower than the referred staggered one, but a lower amount of land is required. Therefore, there would be other opportunities for the remaining land, either for more turbines or other uses.

Acknowledgments: The authors would like to thank the National Council of Research and Development (CNPq), and the University of Denver for the resources provided for the development of this research.

Funding: This work was supported by the National Council of Research and Development CNPq [grant 249258/2013-7].

\section{References}

[1] GWEC - GLOBAL WIND ENERGY COUNCIL. Global Wind Report 2019. March 2020. Available in:< http://gwec.net/publications/globalwind-report-2/>. Access in July. $1^{\text {st }} 2020$.

[2] GWEC - GLOBAL WIND ENERGY COUNCIL. Global Wind Report 2018. April 2019. Available in:<http://gwec.net/publications/globalwind-report-2/>. Access in July. $1^{\text {st }} 2020$.

[3] Brannstrom C, Gorayeb A, Mendes JSM, Loureiro C, Meireles AA, Silva EV, ... \& Oliveira, RF. Is Brazilian wind power development sustainable? Insights from a review of conflicts in Ceará state. Renew Sustain Energy Rev 2017, 67:62-71.

https://doi.org/10.1016/i.rser.2016.08.047

[4] Manwell JF, McGowan J, Rogers A. Wind energy explained: theory, design, and application. 2nd ed., 677p., 2009. 
Page 17 of 21 "Aligned and Staggered Layouts: Impact on Wind Farms Land-Use”

[5] Park J, Law KH. A data-driven, cooperative wind farm control to maximize the total production. Applied Energy 2016, 165: 151-165. https://doi.org/10.1016/i.apenergy.2015.11.064

[6] González JS, Payán MB, Santos JR, Rodríguez AGG. Maximizing the overall production of wind farms by setting the individual operating point of wind turbines. Renewable Energy 2015, 80: 219-229. https://doi.org/10.1016/j.renene.2015.02.009

[7] Gil MDP, Alías CG, Gomis-Bellmunt O, Sumper A. Maximum wind power plant generation by reducing the wake effect. Energy Conv Manag 2015, 101:73-84. https://doi.org/10.1016/i.enconman.2015.05.035

[8] Lee J, Son E, Hwang B, Lee S. Blade pitch angle control for aerodynamic performance optimization of a wind farm. Renew Energy 2013, 54:124-130. https://doi.org/10.1016/i.renene.2012.08.048

[9] Rodrigues RV, Lengsfeld C. Development of a Computational System to Improve Wind Farm Layout, Part I: Model Validation and Near Wake Analysis. Energies 2019, 12(5):940. https://doi.org/10.3390/en12050940

[10] Rodrigues RV, Lengsfeld C. Development of a Computational System to Improve Wind Farm Layout, Part II: Wind Turbine Wakes Interaction. Energies 2019, 12(7):1328. https://doi.org/10.3390/en12071328

[11] Rodrigues RV, Lengsfeld C. Development of a Computational System to Optimize Wind Farm Layout. 35th AIAA Applied Aerodynamics Conference 2017, p. 4212. https://doi.org/10.2514/6.2017-4212

[12] Rodrigues, RV, Lengsfeld C. Automated Gradient-Based Optimization to Maximize Wind Farms Land-Use. 36th AIAA Applied Aerodynamics Conference 2018, p. 3826. https://doi.org/10.2514/6.2018-3826

[13] Chowdhurry S, Messac JZ, Castillo L. Unrestricted wind farm layout optimization (UWFLO): Investigating key factors influencing the maximum power generation. Renewable Energy 2012, 38:16-30. https://doi.org/10.1016/i.renene.2011.06.033

[14] Vasel-Be-Hagh A, Archer CL. Wind farm hub height optimization. Applied Energy 2017, 195:905-921. https://doi.org/10.1016/i.apenergy.2017.03.089

[15] Lee J, Son E, Hwang B, Lee S. Blade pitch angle control for aerodynamic performance optimization of a wind farm. Renewable Energy 2013, 54: 124-130. https://doi.org/10.1016/i.renene.2012.08.048

[16] Kazda J, Zendehbad M, Jafari S, Chokani N, Abhari RS. Mitigating adverse wake effects in a wind farm using non-optimum operational conditions. Journal of Wind Engineering and Industrial Aerodynamics 2016, 154:76-83. https://doi.org/10.1016/i.jweia.2016.04.004

[17] Fleming P, Gebraad PMO, Lee S, Wingerden JW, Johnson K, Churchfield M, Michalakes J, Spalart P, Moriarty P. Simulation comparison of wake mitigation control strategies for a two-turbine case. Wind Energy 2015, 18:2135-2143. https://doi.org/10.1002/we.1810

[18] Fleming P, Ning A, Gebraad PMO, Dykes K. Wind plant system engineering through optimization of layout and yaw control. Wind Energy 2016, 19:329-344. https://doi.org/10.1002/we.1836 
Page 18 of 21 "Aligned and Staggered Layouts: Impact on Wind Farms Land-Use"

[19] Gebraad PMO, Teeuwisse FW, van Wingerden JW, Fleming PA, Ruben SD, Marden JR, Pao LY. Wind plant power optimization through yaw control using a parametric model for wake effects-a CFD simulation study. Wind Energy 2016, 19:95-114. https://doi.org/10.1002/we.1822

[20] Gebraad PMO, Thomas JJ, Ning A, Fleming P, Dykes K. Maximization of the annual energy production of wind power plants by optimization of layout and yaw-based wake control. Wind Energy 2017, 20: 97-107. https://doi.org/10.1002/we.1993

[21] Park J, Law KH. Layout optimization for maximizing wind farm power production using sequential convex programming. Applied Energy 2015, 151:320-334. https://doi.org/10.1016/i.apenergy.2015.03.139

[22] Son E, Lee S, Hwang B, Lee S. Characteristics of turbine spacing in a wind farm using an optimal design process. Renewable Energy 2014, 65: 245-249. https://doi.org/10.1016/i.renene.2013.09.022

[23] Stevens RJAM, Hobbs BF, Ramos A, Meneveau C. Combining economic and fluid dynamic models to determine the optimal spacing in very large wind farms. Wind Energy 2017, 20:466-477. https://doi.org/10.1002/we.2016

[24] Meyers J, Meneveau C. Optimal turbine spacing in fully developed wind farm boundary layers. Wind Energy 2012, 15:305-317. https://doi.org/10.1002/we.469

[25] Stevens, RJAM. Dependence of optimal wind turbine spacing on wind farm length. Wind Energy 2016,19(4):651-663. https://doi.org/10.1002/we.1857

[26] Yang X., Sotiropoulos F. LES investigation of infinite staggered wind-turbine arrays. Journal of Physics: Conference Series 2014, 555(1): 012109. https://doi.org/10.1088/1742$\underline{6596 / 555 / 1 / 012109}$

[27] Wu YT, Porté-Agel F. Simulation of Turbulent Flow Inside and Above Wind Farms: Model Validation and Layout Effects. Boundary-Layer Meteorology 2013, 146:181-205. https://doi.org/10.1007/s10546-012-9757-y

[28] Stevens RJAM, Gayme D, Meneveau C. Effects of turbine spacing on the power output of extended wind-farms. Wind Energy 2016, 19(2):359-370. https://doi.org/10.1002/we.1835

[29] Tian W, Ozbay A, Hu H. An experimental investigation on the wake interferences among wind turbines sited in aligned and staggered wind farms. Wind Energy 2018, 21(2):100-114. https://doi.org/10.1002/we.2147

[30] Draper S, Nishino T. Centred and staggered arrangements of tidal turbines. Journal of Fluid Mechanics 2014, 739:72-93. https://doi.org/10.1017/jfm.2013.593

[31] Markfort C, Zhang W, Porté-Agel F. Turbulent flow and scalar transport through and over aligned and staggered wind farms. Journal of Turbulence 2012, 13(1):1-36. https://doi.org/10.1080/14685248.2012.709635

[32] Chamorro LP, Arndt REA, Sotiropoulos F. Turbulent Flow Properties Around a Staggered Wind Farm. Boundary-Layer Meteorology 2011, 141(3), 349-367. https://doi.org/10.1007/s10546-011-9649-6

[33] Hamilton, N., Melius, M., \& Cal, R. (2015). Wind turbine boundary layer arrays for Cartesian and staggered configurations- Part I, flow field and power measurements. Wind Energy, 18(2), 277-295. https://doi.org/10.1002/we.1697 
Page 19 of 21 "Aligned and Staggered Layouts: Impact on Wind Farms Land-Use"

[34] Hamilton N, Tutkun M, Cal R. Wind turbine boundary layer arrays for Cartesian and staggered configurations: Part II, low-dimensional representations via the proper orthogonal decomposition. Wind Energy 2015, 18(2):297-315.

https://doi.org/10.1002/we.1719

[35] Guirguis D, Romero DA, Amon CH. Toward efficient optimization of wind farm layouts: Utilizing exact gradient information. Applied Energy 2016, 179: 110-123. https://doi.org/10.1016/i.apenergy.2016.06.101

[36] Guirguis D, Romero DA, Amon CH. Gradient-based multidisciplinary design of wind farms with continuous-variable formulations. Applied Energy 2017, 197: 279-291. https://doi.org/10.1016/i.apenergy.2017.04.030

[37] Schepers, J.G.; Boorsma, K.; Cho, T.; Gomez-Iradi, S.; Schaffarczyk, P.; Jeromin, A.; Shen, W.Z.; Lutz, T.; Meister, K.; Stoevesandt, B.; et al. Final Report of IEA Task 29, Mexnet (Phase 1): Analysis of Mexico Wind Tunnel Measurements. Available online: https://www.um.edu.mt/library/oar//handle/123456789/24132 (accessed on 11 March 2019).

[38] Hansen, M. O. (2015). Aerodynamics of wind turbines. Routledge.

[39] Bertagnolio, F., Sørensen, N. N., Johansen, J., \& Fuglsang, P. (2001). Wind turbine airfoil catalogue. (Denmark. Forskningscenter Risoe. Risoe-R; No. 1280(EN)). Technical report, August 2001, 151p.

[40] USGS - United States Geological Survey: The US Wind Turbine Database. Available in <https://eerscmap.usgs.gov/uswtdb/viewer/\#5.08/36.5/-98.23>.

[41] Sharma V, Cortina G, Margairaz F, Parlange M., Calaf M. Evolution of flow characteristics through finite-sized wind farms and influence of turbine arrangement. Renewable Energy 2018, 115:1196-1208. https://doi.org/10.1016/j.renene.2017.08.075

[42] Uchida T, Ohya Y. Large-eddy simulation of turbulent airflow over complex terrain. Journal of wind engineering and industrial aerodynamics 2003, 91(1-2): 219-229.

https://doi.org/10.1016/s0167-6105(02)00347-1

[43] Antonini EG, Romero DA, Amon CH. Optimal design of wind farms in complex terrains using computational fluid dynamics and adjoint methods. Applied Energy 2020, 261:114426. https://doi.org/10.1016/j.apenergy.2019.114426

[44] Veers P, Dykes K, Lantz E, Barth S, Bottasso CL, Carlson O, Clifton A, Green J, Green P, Holttinen $\mathrm{H}$, Laird D, Lehtomäki V, Lundquist JK, Manwell J, Marquis M, Meneveau C, Moriarty P, Munduate X, Muskulus M, Naughton J, Pao L, Paquette J, Peinke J, Robertson A, Rodrigo JS, Sempreviva AM, Smith JC, Tuohy A, Wiser R. Grand challenges in the science of wind energy. Science 2019, 366(6464), eaau2027. https://doi.org/10.1126/science.aau2027 
Page 20 of 21 "Aligned and Staggered Layouts: Impact on Wind Farms Land-Use"

\section{Appendix}

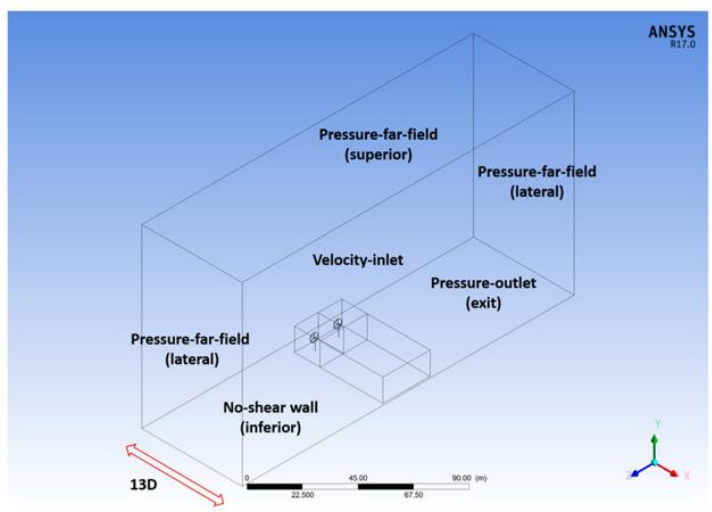

(a)

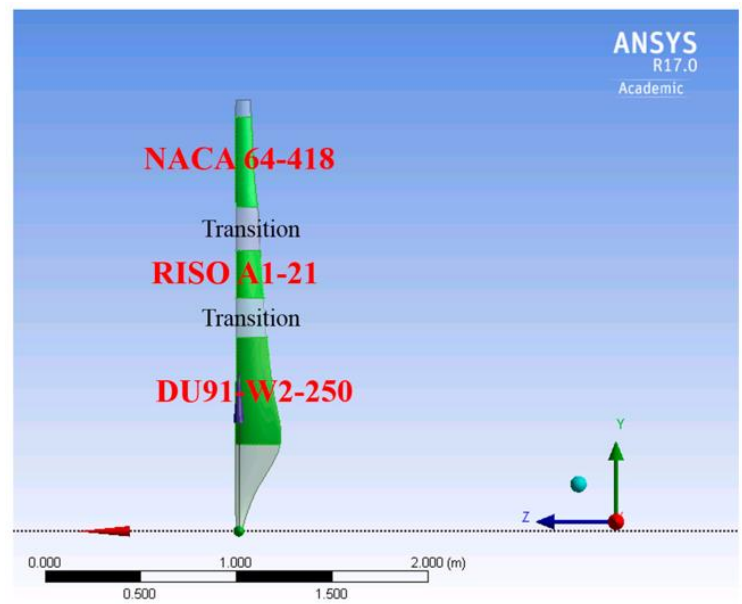

(c)

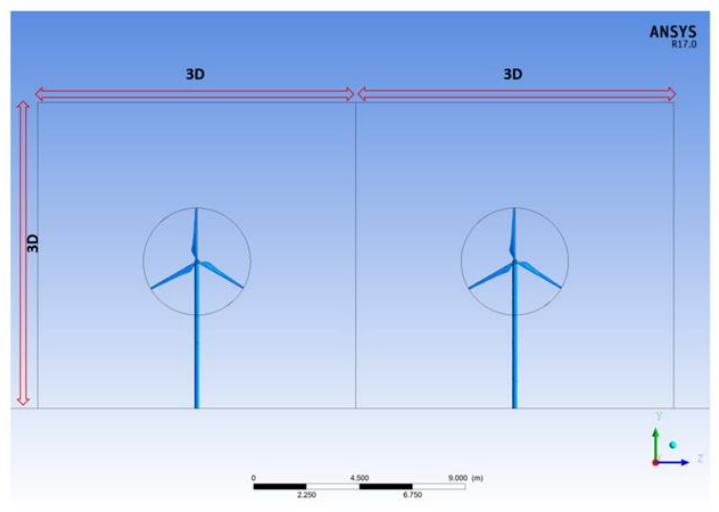

(b)

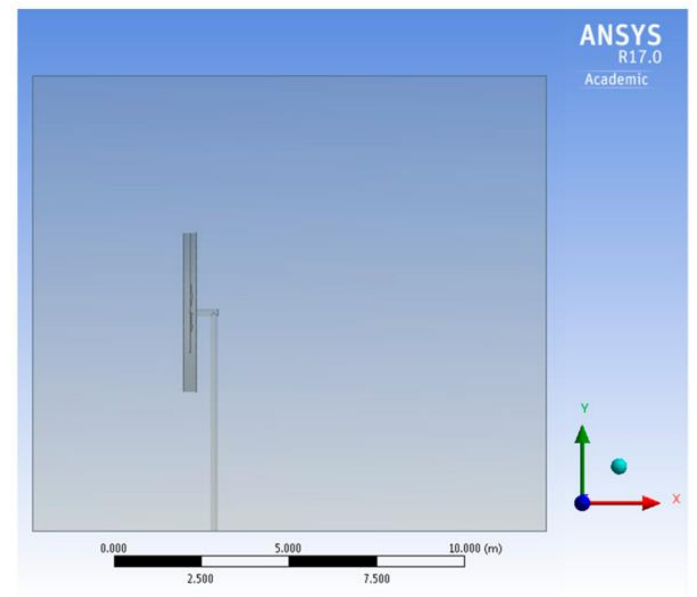

(d)

Figure 1. Geometry of the physical domain and wind turbines showing: a) Physical domain and boundary conditions; b) Front view of the wind turbines; c) Blade geometry; d) Lateral view of the near wake. The figure was adapted from reference [10]. 
Page 21 of 21 "Aligned and Staggered Layouts: Impact on Wind Farms Land-Use"

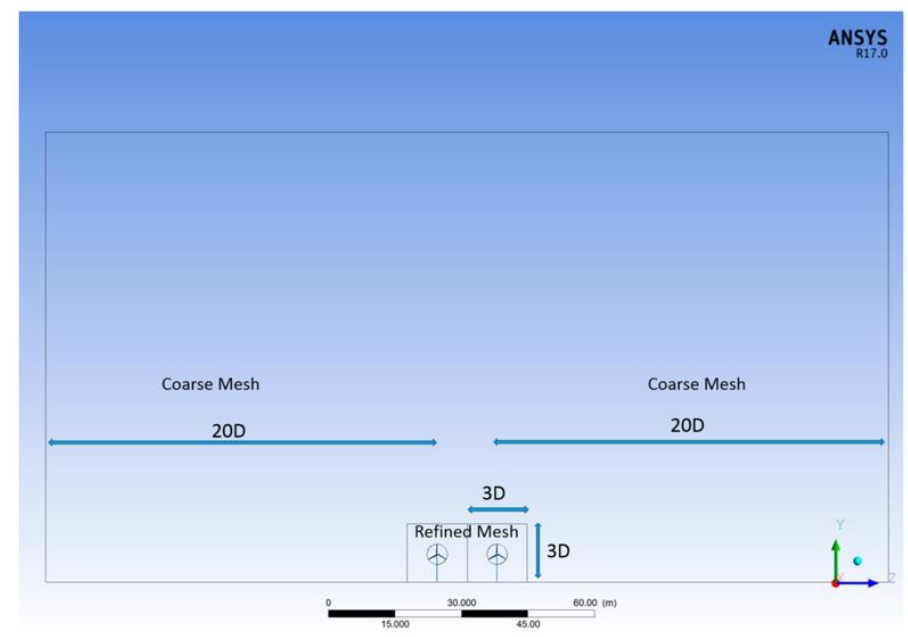

(a)

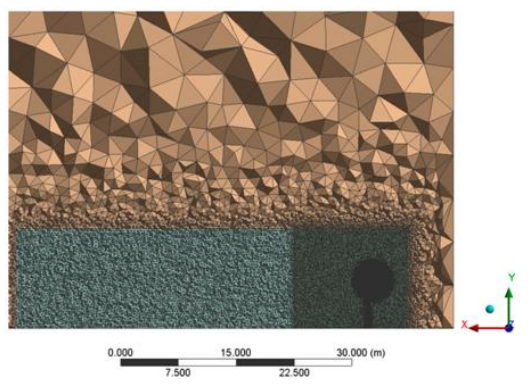

(b)

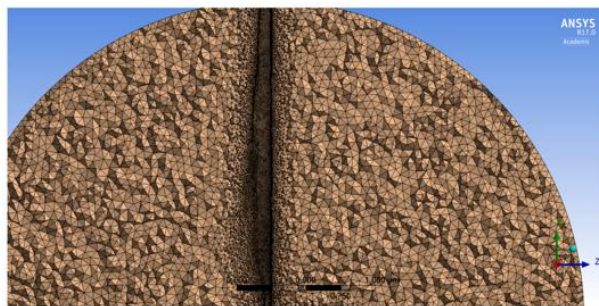

(d)

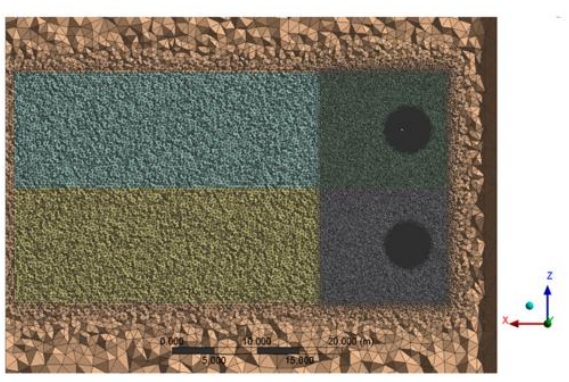

(c)

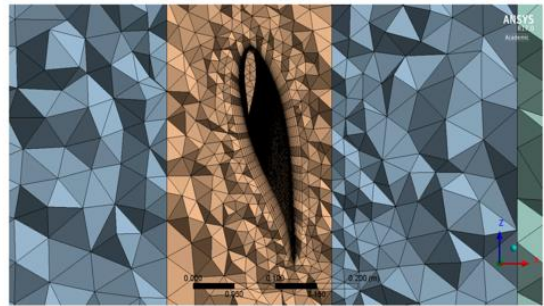

(e)

Figure 2. Physical domain and computational mesh of the physical domain showing: a) Front view of the physical domain; b) Lateral view of the mesh showing the wake; c) Top view of the mesh of the wake; d) Mesh of the central rotative disc; e) Mesh close to the rotor, showing inflation layers. The figure was extracted from reference [10]. 